\title{
Kupffer cells decrease metastasis of colon cancer cells to the liver in the early stage
}

\author{
HIDEKI MATSUMURA, TADASHI KONDO, KOICHI OGAWA, TAKAFUMI TAMURA, \\ KIYOSHI FUKUNAGA, SOICHIRO MURATA and NOBUHIRO OHKOHCHI
}

\author{
Department of Surgery, Doctoral Program in Clinical Science, Graduate School of Comprehensive \\ Human Sciences, University of Tsukuba, Tsukuba, Ibaraki 305-8575, Japan
}

Received July 18, 2014; Accepted August 27, 2014

DOI: $10.3892 /$ ijo.2014.2662

\begin{abstract}
Although Kupffer cells (KCs) play an important role in the liver's immune response, their role in colon cancer metastasis to the liver is unclear. We here analyzed the relationship between KCs and tumor cells (TCs) in colon cancer metastasis to the liver. Fischer 344 (F344) rats were divided into control group ( $\mathrm{KC}+$ group) and $\mathrm{KC}$ elimination group ( $\mathrm{KC}$ - group), in which $\mathrm{KC}$ elimination was induced by $\mathrm{Cl}_{2} \mathrm{MDP}$ liposome injection. RCN-H4 colon cancer cells were injected into the rats of both groups, and the relationship between the two types of cells was observed by intravital microscopy (IVM) for $6 \mathrm{~h}$. Moreover, to investigate the effect of $\mathrm{KCs}$ on liver metastasis formation, $\mathrm{KCs}$ were eliminated at different time points before and after the TC injection. The number of metastatic nodules 2 weeks after the injection was evaluated. In the $\mathrm{KC}$ - group, IVM revealed that the number of adherent TCs had increased 1.5 -fold at $6 \mathrm{~h}$ after the TC injection as compared with in the $\mathrm{KC}+$ group. Moreover, in the $\mathrm{KC}+$ group, $74 \%$ of the $\mathrm{TCs}$ adhered to the $\mathrm{KCs}$, and $\mathrm{KC}$ activation and $\mathrm{KC}$ phagocytosis of the TCs were observed. Two weeks after the injection, the number of metastatic nodules was significantly increased in rats in which the $\mathrm{KCs}$ had been eliminated before the injection, but not in rats in which the $\mathrm{KCs}$ had been eliminated after the injection. KC activation and $\mathrm{KC}$ phagocytosis of TCs decreased colon cancer cell metastasis to the liver.
\end{abstract}

\section{Introduction}

Colorectal cancer (CRC) is one of the most common cancers worldwide (1). The high morbidity and mortality associated with CRC is frequently caused by development of metastasis,

Correspondence to: Professor Nobuhiro Ohkohchi, Department of Surgery, Doctoral Program in Clinical Science, Graduate School of Comprehensive Human Sciences, University of Tsukuba, Tennodai 1-1-1, Tsukuba, Ibaraki 305-8575, Japan

E-mail: nokochi3@md.tsukuba.ac.jp

Key words: colon cancer, intravital microscopy, Kupffer cell, liver metastasis, phagocytosis i.e., liver metastasis (2). This liver metastasis determines the survival rates of CRC patients. The development of liver metastasis comprises many steps: proliferation of the primary tumor, transfer to the circulating blood, adhesion to the liver sinusoids, and extravasation and proliferation into the liver (3). Adhesion of the circulating tumor cells (TCs) to the liver sinusoids is the most important step, and thus, suppression of this TC adhesion is crucial for the control of liver metastasis. Several authors have focused on the various steps of liver metastasis in animal models, and Kupffer cells (KCs) have been revealed to play an important role in the metastasis (4-6). KCs had a promotive effect on liver metastasis; for example, the release of inflammatory cytokines and matrix metalloproteinase by $\mathrm{KCs}$ caused facilitation of adhesion, extravasation, and proliferation of TCs (7-11). On the other hand, a suppressive effect of KCs on liver metastasis was demonstrated by their capacity to kill TCs (12-16). Therefore, the role of KCs in liver metastasis remains controversial. The previous studies analyzed data obtained from fixed specimens; i.e., they did not observe TCs in real time. However, with intravital microscopy (IVM), the interaction of KCs and TCs in the same location can be consecutively observed in real time. We sought, therefore, to analyze in real time the relationship between KCs and TCs in liver metastasis by means of IVM.

\section{Materials and methods}

Animals. Male Fischer 344 (F344) rats, weighing 200-250 g, were obtained from CLEA Japan, Inc. (Tokyo, Japan). The animal experiments were carried out in a humane manner after approval was received from the Animal Experiment Committee of the University of Tsukuba.

Cell lines. RCN-H4 cells $(17,18)$, derived from liver metastasis of an F344 rat colon adenocarcinoma cell line, were provided by the Riken Cell Bank (Ibaraki, Japan). The cells were maintained in RPMI-1640 medium supplemented with $10 \%$ heat-inactivated FBS, $100 \mathrm{U} / \mathrm{ml}$ penicillin $\mathrm{G}$, and $100 \mathrm{~g} / \mathrm{ml}$ streptomycin in humidified $95 \%$ air- $5 \% \mathrm{CO}_{2}$ at $37^{\circ} \mathrm{C}$.

KC elimination. $\mathrm{KCs}$ were eliminated by use of $\mathrm{Cl}_{2} \mathrm{MDP}$ liposomes, as reported by van Rooijen et al (19). The 
- $\mathrm{KC}+\operatorname{group}(\mathrm{n}=6)$

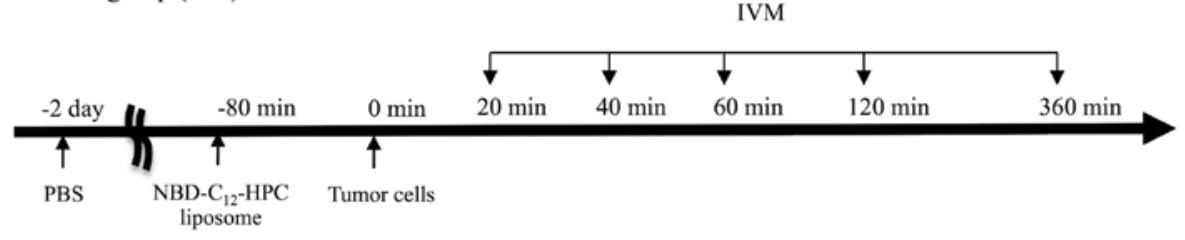

- KC- group $(\mathrm{n}=6)$

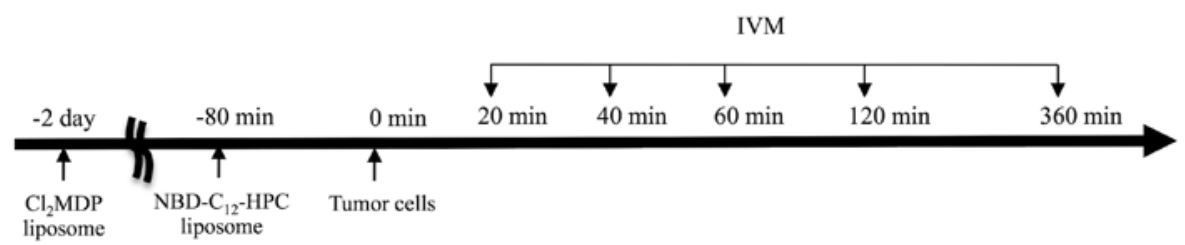

Figure 1. Intravital microscopy (IVM) model. $\mathrm{RCN}-\mathrm{H} 4$ cells $\left(5 \times 10^{6}\right)$ were injected into the experimental rats via the left carotid artery. The rats were divided into two groups: the control group (KC+ group) and $\mathrm{KC}$ elimination group (KC- group).

liposomes were injected into the rats via the tail vein $(1 \mathrm{ml} / \mathrm{rat})$. Twenty-four hours after the injection, no KCs were found. Repopulation of the KCs started at day 3 after the injection and was completed at day 8 (20).

IVM model. The rats were divided into two groups: the control group ( $\mathrm{KC}+$ group; $\mathrm{n}=6)$ and the $\mathrm{KC}$ elimination group ( $\mathrm{KC}$ - group; $\mathrm{n}=6$ ). In the $\mathrm{KC}+$ group, calcium- and magnesium-free PBS (CMF-PBS) was injected via the tail vein $(1 \mathrm{ml} / \mathrm{rat}) 48 \mathrm{~h}$ before the operation. In the $\mathrm{KC}$ - group, $\mathrm{Cl}_{2} \mathrm{MDP}$ liposomes were injected intravenously via the tail vein $(1 \mathrm{ml} / \mathrm{rat}) 48 \mathrm{~h}$ before the operation.

Fluorescence labeling for IVM(labeling of KCs). As previously reported, $\mathrm{KCs}$ were labeled with fluorescence dye by means of the liposome entrapment method (21). Fluorescently labeled phosphatidylcholine was incorporated into the liposomes according to the method of Watanabe et al (22). The fluorescent pigment used was 2-(12-(7-nitrobenz-2-oxa-1,3-diazol-4-yl) amino)dodecanoyl-1-hexadecanoyl-sn-glycero-3-phosphocholine (NBD- $\mathrm{C}_{12}$-HPC) (Molecular Probes, Eugene, OR, USA). Eighty minutes before the TC injection, the liposomes $(4 \mathrm{ml} / \mathrm{kg})$ were administered via a carotid artery catheter. After that, the $\mathrm{KCs}$ in the rat livers were stained and were clearly delineated in the fluorescent IVM image.

Labeling of TCs. After trypsinization, the TCs were washed with CMF-PBS and kept in serum-free medium (RPMI-1640) for $60 \mathrm{~min}$ for reconstitution of the cell surfaces. During reconstitution, the cells were incubated with rhodamine 6G (10-7 M; Sigma-Aldrich Japan, Tokyo, Japan) to label them for the fluorescence microscopy. Subsequent to rhodamine-6G staining, the percentage of living cells exceeded $90 \%$, as assessed by the trypan blue exclusion method. After a wash with CMF-PBS, the cells were resuspended as a single-cell solution in CMF-PBS at a final concentration of $5 \times 10^{6}$ cells $/ \mathrm{ml}$. No detrimental influence of the preparation on the cells' migratory or adhesive activity was observed.
IVM. IVM were performed as previously reported (21). The rats were tracheotomized under isoflurane-induced anesthesia. After a transverse laparotomy, the left hepatic lobe was exteriorized and placed on a plate specially designed to minimize movements caused by respiration and then covered with a gridded coverslip (Olympus Corporation, Tokyo, Japan) (23). Using the gridded coverslips, selected regions of interest could be relocated at later time points. The TCs $\left(5 \times 10^{6}\right.$ cells $)$ were intra-arterially injected for $60 \mathrm{sec}(24)$. TC injection via portal vein caused portal tumor embolism, therefore we took a conscious dicision to TC injection via intra-artery, as reported by other authors $(24,25)$. This route of cell application was reported not to influence the adhesive behavior of the cells within the liver sinusoids (26). The circulating TCs in the sinusoids were observed at $30 \mathrm{sec}$ after the end of the TC injection. IVM was performed using a modified microscope (BX30 FLA-SP; Olympus Corporation). The hepatic microcirculation was recorded by means of a CCD camera (DVC-0; DVC, Austin, TX, USA) and a digital video recorder (GV-HD700/1; Sony, Tokyo, Japan) for offline analysis. Using objective lenses (10x 0.3 - 20x 0.7; Olympus Corporation), a final magnification of $\times 325-x 650$ was achieved on the video screen. In each rat, analysis of the liver microcirculatory parameters was performed in 10 randomly selected acini at 20 , 40, 60, 120, and $360 \mathrm{~min}$ after the TC injection (Fig. 1). The observation time for each field was $30 \mathrm{sec}$. The grid number was recorded, so that the same acini could be observed at each time point. At the end of the observation, the rats were euthanized by exsanguination. The microcirculatory parameters were quantitatively assessed using WinROOF imaging software (version 5.0; Mitani Shoji Co., Ltd, Tokyo, Japan).

Microcirculatory analysis of KCs and TCs. The following parameters were analyzed: i) the number of adherent TCs, i.e., the TCs firmly adherent to the sinusoids for longer than $20 \mathrm{sec}$ [The number of adherent TCs in the scanned acini was counted and the results were expressed as the number of adherent TCs per field ( 1 field $\left.=\sim 0.2 \mathrm{~mm}^{2}\right)$ ]; ii) the number of TCs adherent to KCs, i.e., the TCs detected at the same locations as the KCs; and iii) the number of KCs. 




Figure 2. Kupffer cell (KC) elimination model before and after tumor cell (TC) injection. RCN-H4 cells $\left(5 \times 10^{6}\right)$ were injected into the experimental rats via the left carotid artery. The rats were divided into five groups: the control group ( $\mathrm{KC}+$ group) without $\mathrm{Cl}_{2} \mathrm{MDP}$ liposome injection ( $\left.\mathrm{n}=6\right)$ and the $\mathrm{KC}$ elimination groups (KC- group) with $\mathrm{Cl}_{2} \mathrm{MDP}$ liposome injection 2 days before the TC injection $(\mathrm{n}=6)$ and 1,3 , and 7 days after the TC injection (KC $1 \mathrm{D}$ - group, $\mathrm{KC} 3 \mathrm{D}$ - group, and KC 7D- group, respectively; $\mathrm{n}=6 \mathrm{each}$ ). The liver tissue was excised for histologic examination 14 days after the TC injection.

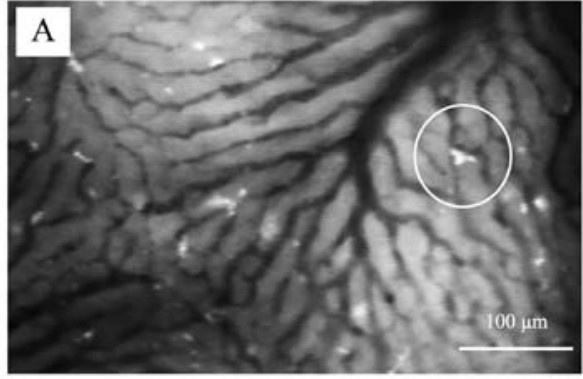

Kupffer cells

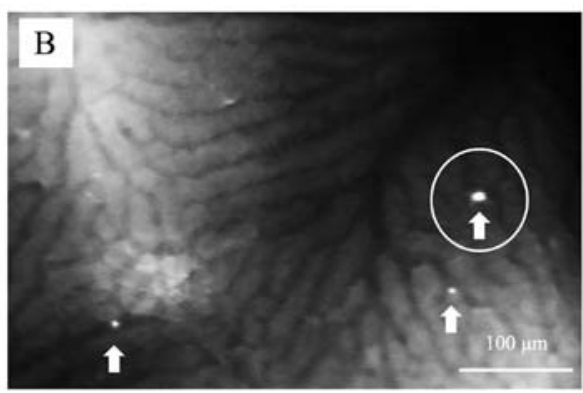

Tumor cells

Figure 3. In vivo observation of Kupffer cells (KCs) and tumor cells (TCs). Video images of (A) KCs and (B) TCs in liver acini after the TC injection. The field is $\sim 0.2 \mathrm{~mm}^{2}$. The same acinus was repeatedly observed at different time points through use of gridded coverslips. The video images show (A) the acini of fluorescently stained KCs, and (B) the acini of fluorescently stained TCs (arrows). The white circles indicate an adherent TC in the same location as a $\mathrm{KC}$.

Biochemical analysis. As markers of $\mathrm{KC}$ activation, tumor necrosis factor (TNF) $\alpha$ and interleukin (IL)- $1 \beta$ levels in liver tissues were measured $6 \mathrm{~h}$ after the TC injection using a commercial enzyme-linked immunosorbent assay kit (R\&D Systems, Minneapolis, MN, USA).

Transmission electron microscopy. KCs after the TC injection were assessed by transmission electron microscopy. Two hours after the injection, the livers were quickly resected. Tissue samples from the right lobe were cut into $1-\mathrm{mm}^{3}$ cubes and stored in $2.5 \%$ glutaraldehyde. The specimens were post-fixed with osmium tetroxide, dehydrated through a graded alcohol series, and embedded in Epon mixture. Ultrathin sections were prepared using an Ultracut S microtome (Leica Aktiengesellschaft, Vienna, Austria) and mounted on copper grids.
The sections were treated with uranyl acetate and lead citrate to enhance the contrast. Specimens were examined using a Hitachi H-7000 transmission electron microscope (Hitachi, Tokyo, Japan).

$K C$ elimination model before and after TC injection. To evaluate which timing of the $\mathrm{KC}$ elimination and $\mathrm{TC}$ injection was involved in liver metastasis, the rats were divided into five groups: the $\mathrm{KC}+$ group without the $\mathrm{Cl}_{2} \mathrm{MDP}$ liposome injection $(\mathrm{n}=6)$; the $\mathrm{KC}$ - group with the $\mathrm{Cl}_{2} \mathrm{MDP}$ liposome injection 2 days before the TC injection $(n=6)$; and the $\mathrm{KC}$ - group with the $\mathrm{Cl}_{2} \mathrm{MDP}$ liposome injection 1,3 , and 7 days after the TC injection (KC 1D- group, KC 3D-group, and KC 7D-group, respectively; $n=6$ each; Fig. 2). In all groups, $5 \times 10^{8} \mathrm{RCN}-\mathrm{H} 4$ cells were injected via the left carotid artery. The number of metastatic nodules in the liver was evaluated by hematoxylin and eosin (H\&E) staining of the liver sections obtained 2 weeks after the TC injection.

Histologic analysis. Liver tissues were obtained from each rat, fixed with $10 \%$ formaldehyde, and embedded in paraffin. The left and medial lobes were evenly cut into 10 slices. Thin sections ( $4 \mu \mathrm{m}$ ) were prepared and stained with H\&E. The number of the metastatic nodules was assessed using WinROOF software.

Statistical analysis. All data were expressed as the means \pm standard errors of the mean (SEMs). The Mann-Whitney test and analysis of variance were used, followed by the Scheffé's test. $\mathrm{P}<0.05$ was considered significant.

\section{Results}

IVM model. The circulating TCs rapidly adhered to the sinusoids, and some adherent TCs were detected in the same locations as the KCs (Fig. 3A and B). The number of KCs in the sinusoids was significantly decreased in the $\mathrm{KC}$ - group when compared with the $\mathrm{KC}+$ group before the $\mathrm{TC}$ injection (Fig. 4A and B). $\mathrm{Cl}_{2} \mathrm{MDP}$ successfully eliminated $\mathrm{KCs}$ from the liver tissue. No side-effects of $\mathrm{Cl}_{2} \mathrm{MDP}$ administration, such as liver injury, were observed.

Number of adherent TCs in the sinusoids. The total number of adherent TCs in the sinusoids peaked at 20 min after the TC injection and then decreased in both groups (Fig. 5A). 


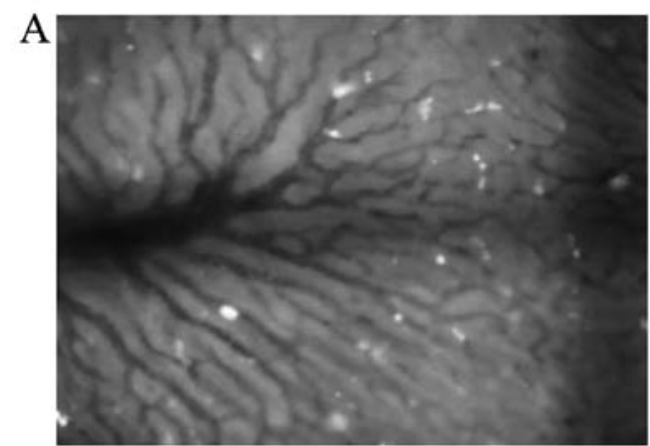

$\mathrm{KC}+$

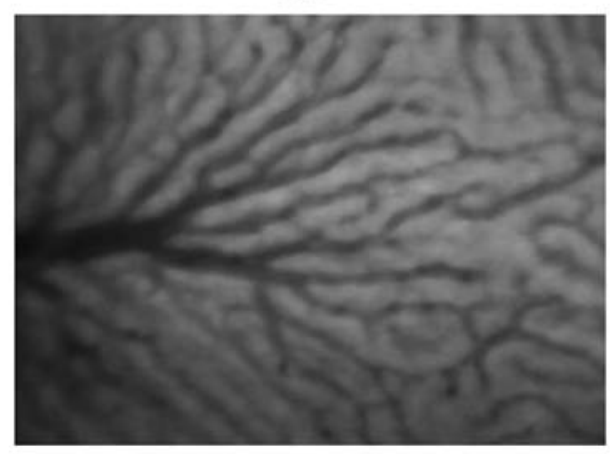

B

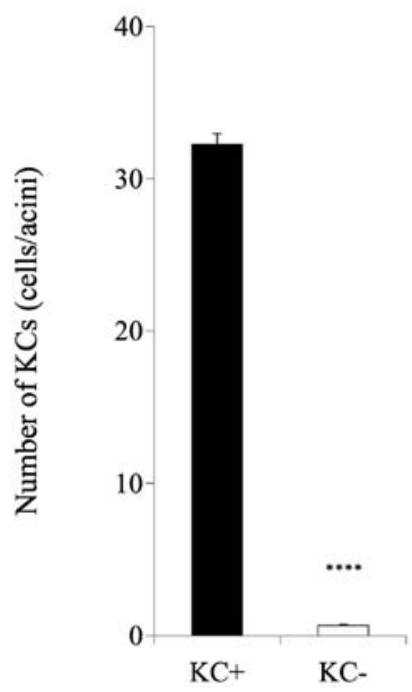

KC-

Figure 4. Elimination of Kupffer cells (KCs). (A) Video images of KCs in liver acini $80 \mathrm{~min}$ after NBD-C $\mathrm{C}_{12}$-HPC liposome injection. The upper figure shows the control group ( $\mathrm{KC}+$ group), and the lower figure, the $\mathrm{KC}$ elimination group (KC-group). In the $\mathrm{KC}+$ group, fluorescently stained $\mathrm{KCs}$ were present in the acini. In contrast, no KCs were present in the KC- group. (B) Bar graph depicting the number of KCs in the sinusoids. The number of KCs in the sinusoids was significantly decreased in the KC- group when compared with that in the KC+ group. Mean \pm standard error of the mean $(\mathrm{SEM}) ; \mathrm{n}=6$. ${ }^{* * * * *} \mathrm{P}<0.0001$, versus $\mathrm{KC}+$ group.

A

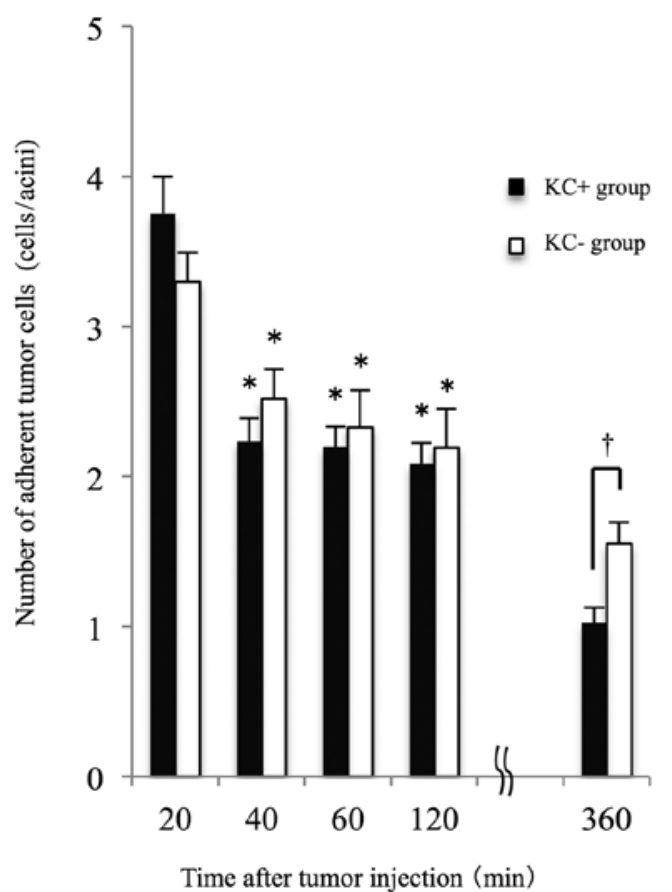

B

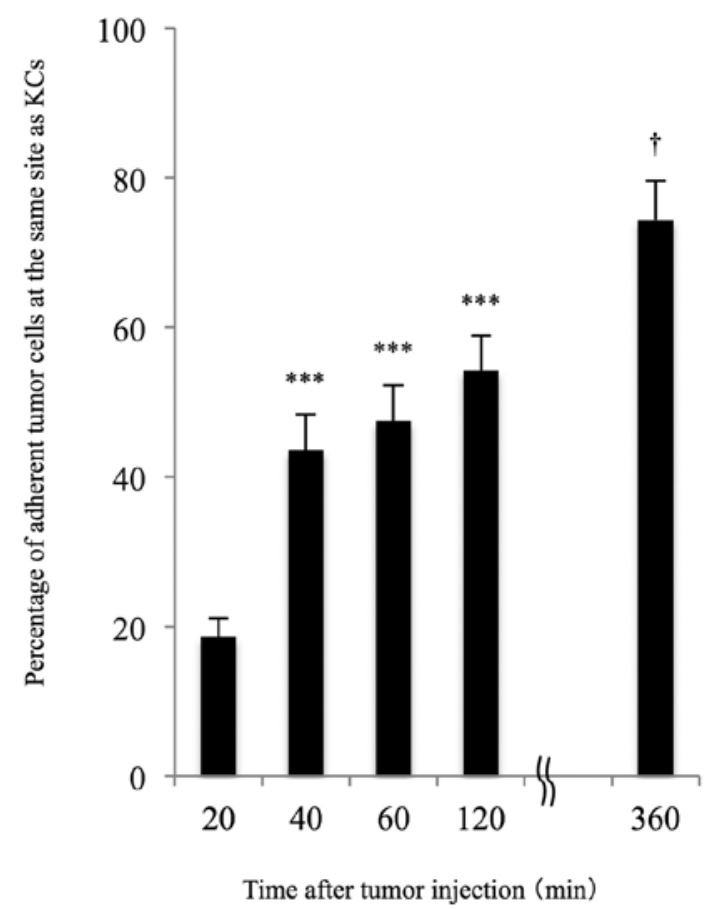

Figure 5. Number of adherent tumor cells (TCs) in the sinusoids. (A) Bar graph depicting the number of adherent TCs in the liver sinusoids. The number of adherent TCs in the sinusoids decreased with time in both groups. In the KC elimination group (KC- group), the number of adherent TCs at 360 min after the TC injection was higher than that in the control group (KC+ group). Mean \pm standard error of the mean (SEM); $\mathrm{n}=6$. ${ }^{*} \mathrm{P}<0.05$, versus 20 min; ${ }^{\dagger} \mathrm{P}<0.05$, versus KC- group. (B) Bar graph depicting the percentage of adherent TCs in the same location as the Kupffer cells (KCs) in the KC+ group. The percentage of adherent TCs in the same location as the KCs tended to increase over time. Mean $\pm \mathrm{SEM} ; \mathrm{n}=6{ }^{* * * *} \mathrm{P}<0.001$, versus $20 \mathrm{~min} ;{ }^{\dagger} \mathrm{P}<0.05$, versus $120 \mathrm{~min}$. 
A

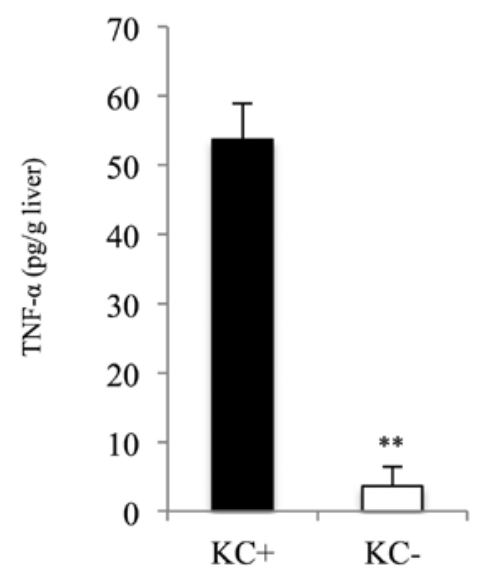

B

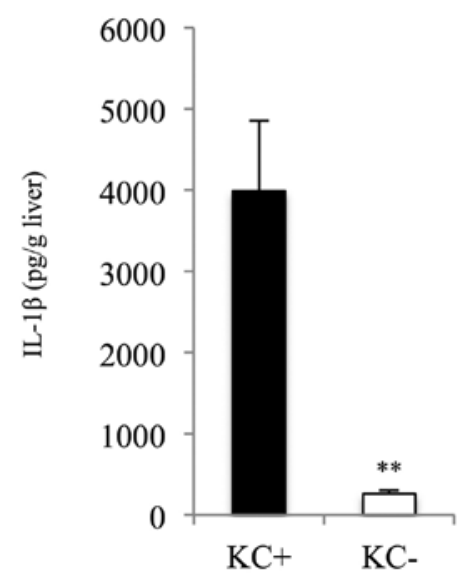

Figure 6. Tumor necrosis factor (TNF)- $\alpha$ and interleukin (IL)-1 $\beta$ levels in liver tissue. Bar graph depicting (A) TNF- $\alpha$ and (B) IL-1 $\beta$ concentrations in liver tissue $6 \mathrm{~h}$ after tumor cell (TC) injection. Both concentrations were significantly increased in the control group (KC+ group). Mean \pm standard error of the mean $(\mathrm{SEM}) ; \mathrm{n}=6$. $^{* *} \mathrm{P}<0.01$, versus $\mathrm{KC}+$ group.
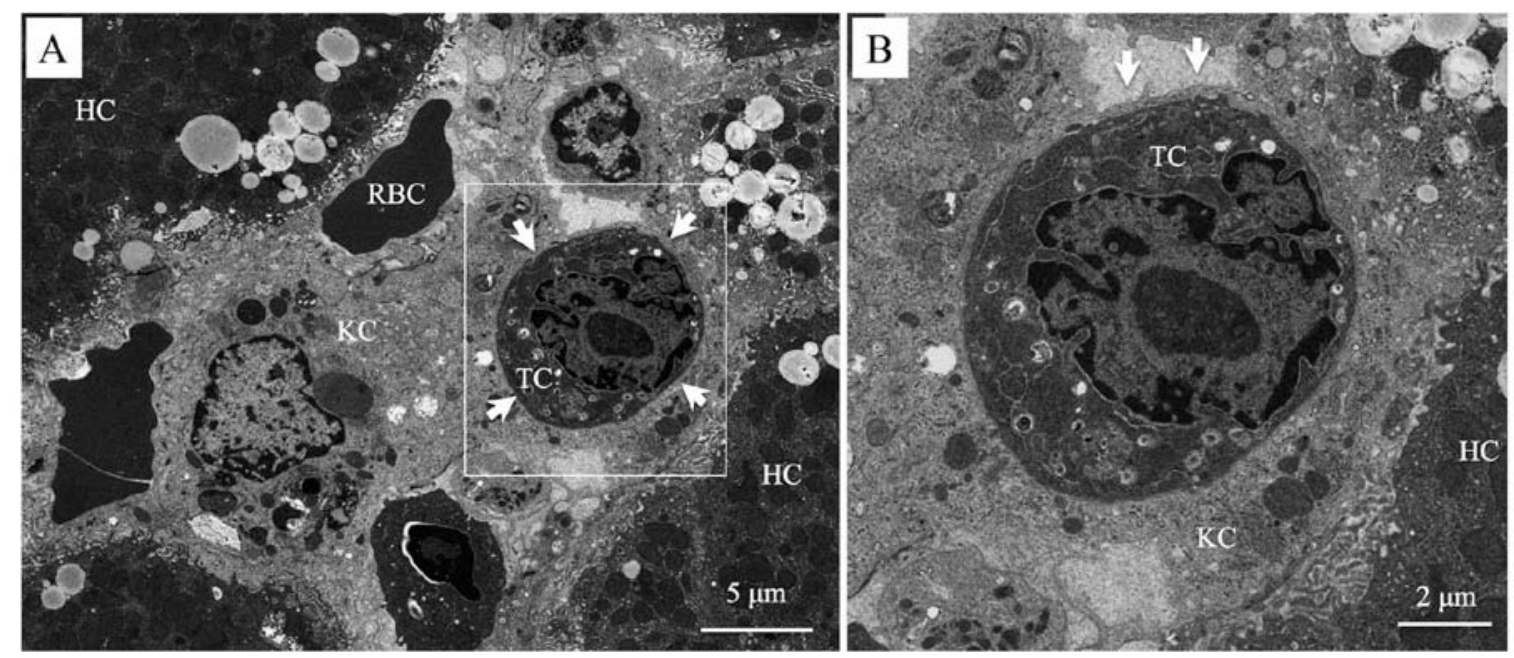

Figure 7. Transmission electron microscopy. (A) Transmission electron microscopy image showing a Kupffer cell (KC) encircling a tumor cell (TC) (arrows) $2 \mathrm{~h}$ after the TC injection in the control group (KC+ group). The white square area is scaled up in Fig. 6B. (B) TC visible in the cell cytoplasm of the KC. The cell membrane of the KC (arrows) was external to the TC. RBC, red blood cell; HC, hepatic cell.

Regardless of the presence of $\mathrm{KCs}$, the total number of adherent TCs was almost the same in both groups until $2 \mathrm{~h}$ after the injection. However, the total number of adherent TCs at $6 \mathrm{~h}$ after the injection in the $\mathrm{KC}+$ group was less than that in the $\mathrm{KC}$ - group. The adherent TCs in the same location as the KCs comprised $19 \%$ of the total number of adherent TCs at $20 \mathrm{~min}$ and increased over time, i.e., by $74 \%$ at $6 \mathrm{~h}$ (Fig. 5B).

TNF- $\alpha$ and IL- $1 \beta$ in liver tissue. The concentrations of TNF- $\alpha$ and IL-1 $\beta$ in the liver tissue were significantly elevated at $6 \mathrm{~h}$ after the $\mathrm{TC}$ injection in the $\mathrm{KC}+$ group (Fig. 6A and B).

Transmission electron microscopy. In the transmission electron microscopy findings, some TCs were adherent to the KCs in the liver sinusoids. All of the TCs were phagocytosed by the KCs (Fig. 7A and B).
$K C$ elimination model before and after TC injection. In the $\mathrm{KC}$ - group, the number of liver metastatic nodules was remarkably increased when compared with that in the $\mathrm{KC}+$ group (Fig. 8A). A large number of metastatic nodules were observed in the portal area. The morphology of the metastatic nodules in both groups was the same (Fig. 8B). In the $\mathrm{KC}+$ group, the number of metastatic nodules was $0.15 \pm 0.04$ per slice for the left and middle liver lobes. In the KC-group, in which $\mathrm{Cl}_{2} \mathrm{MDP}$ liposomes had been administered 2 days before the TC injection, the metastases were markedly increased (57.55 \pm 4.41 ; Fig. 9). In the other three $\mathrm{KC}$ - groups, in which the $\mathrm{Cl}_{2} \mathrm{MDP}$ liposome injection had been administered 1-7 days after the TC injection, there were no significant differences in the number of metastases as compared with the $\mathrm{KC}+$ group (Fig. 9). The numbers of metastatic nodules were $3.91 \pm 0.43,0.19 \pm 0.04$, and $0.19 \pm 0.05$ in the KC 1D-group, KC 3D- group, and KC 7D- group, respectively. 


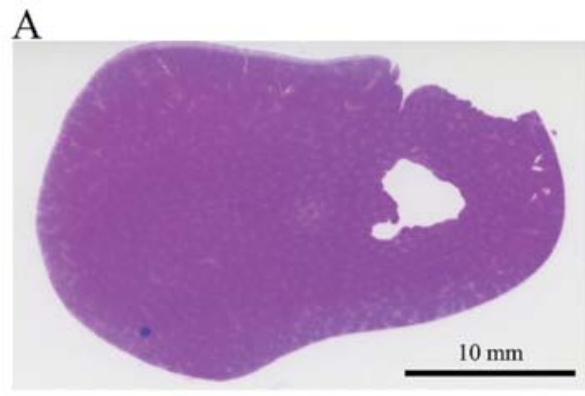

$\mathrm{KC}+$

B

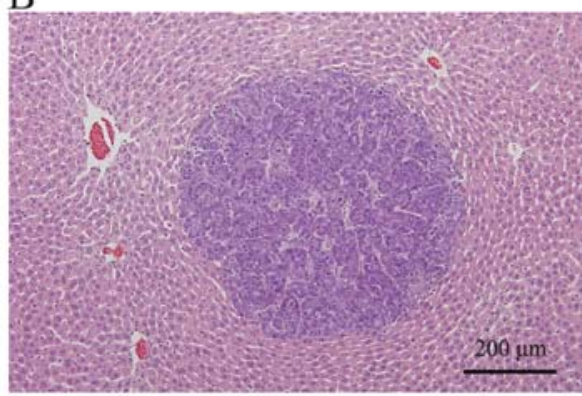

$\mathrm{KC}+$

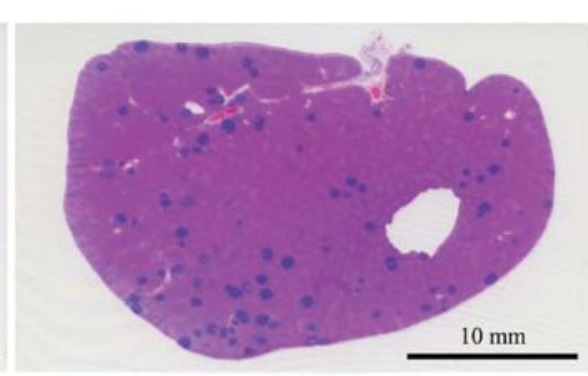

KC-

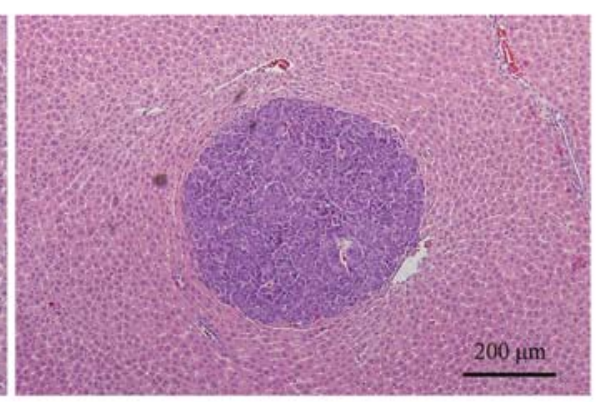

$\mathrm{KC}-$

Figure 8. Liver metastasis at day 14 after tumor cell (TC) injection. Liver tissue was excised 14 days after the TC injection. Thin sections were prepared and stained with hematoxylin and eosin (H\&E). The metastatic nodules were stained blue by hematoxylin. (A) In the loupe view, numerous metastatic nodules were observed in the KC elimination group (KC-group) as compared with in the control group (KC+ group). (B) In the low power field, a large number of metastatic nodules was observed in the portal area. The morphology of the metastatic nodules was the same in both groups.

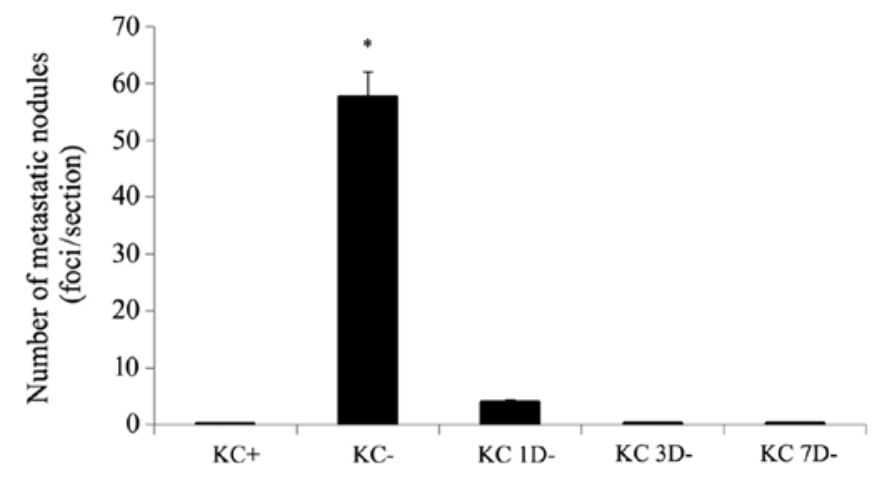

Figure 9. Number of metastatic nodules (administration of $\mathrm{Cl}_{2} \mathrm{MDP}$ liposomes at different time points). Bar graph depicting the number of metastatic nodules. Metastasis was markedly increased in the $\mathrm{KC}$ elimination group (KC- group), in which $\mathrm{Cl}_{2} \mathrm{MDP}$ liposomes had been administered 2 days before the tumor cell (TC) injection. No significant differences were found in any of the groups other than in the KC- group. Mean \pm standard error of the mean (SEM); $\mathrm{n}=6 .{ }^{*} \mathrm{P}<0.05$, versus control group (KC+ group).

\section{Discussion}

Proliferation of TCs in the liver after migration from the primary lesion causes CRC metastases to the liver. Some patients with CRC or CRC liver metastasis had TCs in the circulating blood (27-30). KCs play an important role in liver metastasis; however, whether the role of $\mathrm{KCs}$ in the metastasis is promotive or suppressive remains unclear $(6-16,31,32)$. Previous studies consisted mostly of histologic evaluations of fixed specimens $(31,33,34)$, and the relationship between KCs and TCs in the same individual was not observed in real time. To clarify the role of KCs, especially in the early stage of liver metastasis, we used IVM to observe adhesion of TCs to the liver sinusoids. Our results showed that the total number of adherent TCs was significantly increased by elimination of KCs. Moreover, in the metastasis formation model, the number of liver metastases was increased by elimination of KCs. These results suggested that KCs suppressed liver metastasis. Furthermore, we found that the number of adherent TCs in the sinusoids in the early stage of liver metastasis was strongly related with the formation of the liver metastatic nodules thereafter.

IVM allows for consecutive observation of the same region, and we could observe the adhesion of the TCs to the sinusoids for up to $6 \mathrm{~h}$ after the TC injection. We found that the total number of adherent TCs in the $\mathrm{KC}+$ group decreased time-dependently, and at $6 \mathrm{~h}$ after the TC injection, it was significantly smaller than that in the KC- group. Moreover, in the $\mathrm{KC}+$ group, the percentage of adherent TCs detected at the same locations as the KCs increased time-dependently. These results strongly suggested that the KCs interacted with the TCs, and to elucidate this fact, we used transmission electron microscopy to demonstrate that the KCs phagocytosed the TCs. The result clearly indicated that the TCs adherent to the KCs were caught by the pseudopodia of the KCs and that the KCs phagocytosed the TCs, resulting in the decreased number of adherent TCs after the TC injection. Previous studies observed that a coculture of KCs and TCs led to the formation of pseudopodia in KCs and that the KCs attached to the TCs in vitro (35). Moreover, the TCs that were strongly caught by the pseudopodia of the KCs were phagocytosed and destroyed by the KCs (36). Timmers et al observed that KCs interacted with most injected TCs and phagocytosed most of them in vivo (16). Therefore, it was strongly suggested that 
KCs phagocytosed TCs in the early stage of liver metastasis and suppressed formation of liver metastasis.

$\mathrm{KC}$ phagocytosis of TCs needs activation of the KCs (36). To evaluate the activation of $\mathrm{KCs}$, we investigated the cytokines involved in KCs, i.e., TNF- $\alpha$ and IL-1 $\beta$ (37-39), in liver tissue. In the $\mathrm{KC}+$ group, both cytokines were elevated $6 \mathrm{~h}$ after the TC injection. TCs have been reported to activate $\mathrm{KCs}$; i.e., TCs led to secretion of TNF- $\alpha$ involved in KCs in vitro (33) and to increase of peroxidase activity in $\mathrm{KCs}$ in vivo (40). Moreover, KC activation, which was induced by $\mathrm{OK} 432$, an immunopotentiator prepared from streptococci, led to a decrease in liver metastasis in a rat model (6). It was postulated that this effect resulted from the augmentation of the tumoricidal activity and antigen-presenting activity of the KCs (6). Mise et al reported that OK432 increased the TNF production and tumoricidal activity of KCs in vitro (32). Therefore, the augmentation of $\mathrm{KC}$ tumoricidal activity might be a strategy to prevent liver metastases (6). Bayon et al demonstrated tumoricidal activity of $\mathrm{KCs}$ in vitro using rat colon adenocarcinoma CC531 cells, and reported that TC injection after the elimination of KCs led to increased liver metastasis in vivo study (31). From these reports and our results, we concluded that the activation of KCs was strongly associated with the TC injection.

After clarifying our results that $\mathrm{KCs}$ are necessary to suppress liver metastasis, we next sought to elucidate when the presence of KCs is necessary for suppression of liver metastasis. In the groups in which KCs were eliminated 1-7 days after the TC injection, the number of metastatic nodules was significantly decreased when compared with the group in which KCs were eliminated before the TC injection. It has been reported that circulating TCs were increased by surgical manipulation. Nishizaki et al reported that liver metastasis progressed after surgical manipulation in a VX-2 carcinoma cell line in a rabbit model (41). In clinical studies of patients with resectable CRC, circulating TCs were increased by surgical manipulation, and the presence of the circulating TCs negatively affected the prognosis after surgery (42). In another clinical study, circulating TCs were detected in $20-30 \%$ of patients with liver metastases from CRC before surgery, and the rate was increased to $50 \%$ during liver resection $(27,43)$. Koch et al postulated that intraoperative tumor manipulation, which resulted in an enhanced release of TCs, caused tumor recurrence, at least in patients undergoing liver resection for colorectal metastases (27). Some studies demonstrated that the presence of circulating TCs within $24 \mathrm{~h}$ of CRC resection significantly increased the rate of recurrence $(27,29,30)$. The circulating TCs, which were increased by surgical manipulation, were considered to contribute to the recurrence of liver metastasis following curative surgical resection. These findings suggested that the augmentation of $\mathrm{KC}$ phagocytosis of TCs had the potential to suppress liver metastasis after CRC surgical resection.

To our knowledge, this is the first study to show adhesion between KCs and TCs in real time by using IVM. The TCs adhered to the KCs, and the KCs were then activated and phagocytosed the TCs. We also demonstrated that KCs played a suppressive role in liver metastasis. In this study, the role of $\mathrm{KCs}$ in the early stage of liver metastasis was revealed. Future study of the detailed mechanism of KC phagocytosis of TCs may provide new therapies for the prevention of liver metastasis after curative resection of CRC.

\section{Acknowledgements}

This study was supported in part by the Japanese Ministry of Education, Culture, Sports, Science, and Technology of Japan (MEXT) (Kakenhi no. 25462078). We thank F. Miyamasu for grammatical revision.

\section{References}

1. Parkin DM, Bray F, Ferlay J and Pisani P: Global cancer statistics, 2002. CA Cancer J Clin 55: 74-108, 2005.

2. van der Bij GJ, Bögels M, Otten MA, et al: Experimentally induced liver metastases from colorectal cancer can be prevented by mononuclear phagocyte-mediated monoclonal antibody therapy. J Hepatol 53: 677-685, 2010.

3. Gout $S$ and Huot $\mathrm{J}$ : Role of cancer microenvironment in metastasis: focus on colon cancer. Cancer Microenviron 1: 69-83, 2008.

4. Williams DL, Sherwood ER, McNamee RB, Jones EL and Di Luzio NR: Therapeutic efficacy of glucan in a murine model of hepatic metastatic disease. Hepatology 5: 198-206, 1985.

5. Heuff G, Oldenburg HS, Boutkan H, et al: Enhanced tumour growth in the rat liver after selective elimination of Kupffer cells. Cancer Immunol Immunother 37: 125-130, 1993.

6. Zhang W, Arii S, Sasaoki T, et al: The role of Kupffer cells in the surveillance of tumor growth in the liver. J Surg Res 55: 140-146, 1993.

7. Thomas P, Hayashi H, Zimmer R and Forse RA: Regulation of cytokine production in carcinoembryonic antigen stimulated Kupffer cells by beta-2 adrenergic receptors: implications for hepatic metastasis. Cancer Lett 209: 251-257, 2004.

8. Gangopadhyay A, Lazure DA and Thomas P: Carcinoembryonic antigen induces signal transduction in Kupffer cells. Cancer Lett 118: 1-6, 1997.

9. Gangopadhyay A, Lazure DA and Thomas P: Adhesion of colorectal carcinoma cells to the endothelium is mediated by cytokines from CEA stimulated Kupffer cells. Clin Exp Metastasis 16: 703-712, 1998.

10. Auguste P, Fallavollita L, Wang N, Burnier J, Bikfalvi A and Brodt P: The host inflammatory response promotes liver metastasis by increasing tumor cell arrest and extravasation. Am J Pathol 170: 1781-1792, 2007.

11. Christophi $\mathrm{C}$, Harun $\mathrm{N}$ and Fifis $\mathrm{T}$ : Liver regeneration and tumor stimulation - a review of cytokine and angiogenic factors. J Gastrointest Surg 12: 966-980, 2008.

12. Roh MS, Wang L, Oyedeji C, et al: Human Kupffer cells are cytotoxic against human colon adenocarcinoma. Surgery 108: 400-405, 1990.

13. Curley SA, Roh MS, Feig B, Oyedeji C, Kleinerman ES and Klostergaard J: Mechanisms of Kupffer cell cytotoxicity in vitro against the syngeneic murine colon adenocarcinoma line MCA26. J Leukoc Biol 53: 715-721, 1993.

14. Thomas C, Nijenhuis AM,Dontje B,Daemen T and Scherphof GL: Tumoricidal response of liver macrophages isolated from rats bearing liver metastases of colon adenocarcinoma. J Leukoc Biol 57: 617-623, 1995.

15. Heuff G, Steenbergen JJ, Van de Loosdrecht AA, et al: Isolation of cytotoxic Kupffer cells by a modified enzymatic assay: a methodological study. J Immunol Methods 159: 115-123, 1993.

16. Timmers M, Vekemans K, Vermijlen D, et al: Interactions between rat colon carcinoma cells and Kupffer cells during the onset of hepatic metastasis. Int J Cancer 112: 793-802, 2004.

17. Inoue Y, Kashima Y, Aizawa K and Hatakeyama K: A new rat colon cancer cell line metastasizes spontaneously: biologic characteristics and chemotherapeutic response. Jpn J Cancer Res 82: 90-97, 1991.

18. Okuno K, Hirai N, Lee YS, Kawai I, Shigeoka H and Yasutomi M: Involvement of liver-associated immunity in hepatic metastasis formation. J Surg Res 75: 148-152, 1998.

19. van Rooijen N and Kors N: Effects of intracellular diphosphonates on cells of the mononuclear phagocyte system: in vivo effects of liposome-encapsulated diphosphonates on different macrophage subpopulations in the spleen. Calcif Tissue Int 45: 153-156, 1989. 
20. Bogers WM, Stad RK, Janssen DJ, et al: Kupffer cell depletion in vivo results in clearance of large-sized IgA aggregates in rats by liver endothelial cells. Clin Exp Immunol 85: 128-136, 1991.

21. Tamura T, Kondo T, Pak S, et al: Interaction between Kupffer cells and platelets in the early period of hepatic ischemia-reperfusion injury - an in vivo study. J Surg Res 178: 443-451, 2012.

22. Watanabe R, Munemasa T, Matsumura M and Fujimaki M: Fluorescent liposomes for intravital staining of Kupffer cells to aid in vivo microscopy in rats. Methods Find Exp Clin Pharmacol 29: 321-327, 2007.

23. Kondo T, Okamoto S, Todoroki T, Hirano T, Schildberg FW and Messmer K: Application of a novel method for subsequent evaluation of sinusoids and postsinusoidal venules after ischemia-reperfusion injury of rat liver. Eur Surg Res 30: 252-258, 1998

24. Enns A, Korb T, Schlüter K, et al: Alphavbeta5-integrins mediate early steps of metastasis formation. Eur J Cancer 41 1065-1072, 2005.

25. Schlüter K, Gassmann P, Enns A, et al: Organ-specific metastatic tumor cell adhesion and extravasation of colon carcinoma cells with different metastatic potential. Am J Pathol 169: 1064-1073, 2006.

26. Haier J, Korb T, Hotz B, Spiegel HU and Senninger N: An intravital model to monitor steps of metastatic tumor cell adhesion within the hepatic microcirculation. J Gastrointest Surg 7: 507-514, 2003.

27. Koch M, Kienle P, Hinz U, et al: Detection of hematogenous tumor cell dissemination predicts tumor relapse in patients undergoing surgical resection of colorectal liver metastases. Ann Surg 241: 199-205, 2005.

28. Yamaguchi K, Takagi Y, Aoki S, Futamura M and Saji S: Significant detection of circulating cancer cells in the blood by reverse transcriptase-polymerase chain reaction during colorectal cancer resection. Ann Surg 232: 58-65, 2000.

29. Allen-Mersh TG, McCullough TK, Patel H, Wharton RQ, Glover C and Jonas SK: Role of circulating tumour cells in predicting recurrence after excision of primary colorectal carcinoma. Br J Surg 94: 96-105, 2007.

30. Patel H, Le Marer N, Wharton RQ, et al: Clearance of circulating tumor cells after excision of primary colorectal cancer. Ann Surg 235: 226-231, 2002.

31. Bayón LG, Izquierdo MA, Sirovich I, van Rooijen N, Beelen RH and Meijer S: Role of Kupffer cells in arresting circulating tumor cells and controlling metastatic growth in the liver. Hepatology 23: 1224-1231, 1996.
32. Mise M, Arii S, Higashitsuji H, et al: Augmented local immunity in the liver by a streptococcal preparation, OK432, related to antitumor activity of hepatic macrophages. Immunopharmacology 27: 31-41, 1994.

33. Khatib AM, Auguste P, Fallavollita L, et al: Characterization of the host proinflammatory response to tumor cells during the initial stages of liver metastasis. Am J Pathol 167: 749-759, 2005.

34. Higashi N, Ishii H, Fujiwara T, Morimoto-Tomita M and Irimura $\mathrm{T}$ : Redistribution of fibroblasts and macrophages as micrometastases develop into established liver metastases. Clin Exp Metastasis 19: 631-638, 2002.

35. Yonei Y, Kurose I, Fukumura D, et al: Evidence of direct interaction between Kupffer cells and colon cancer cells: an ultrastructural study of the co-culture. Liver 14: 37-44, 1994.

36. Gardner CR, Wasserman AJ and Laskin DL: Liver macrophage-mediated cytotoxicity toward mastocytoma cells involves phagocytosis of tumor targets. Hepatology 14: 318-324, 1991.

37. Decker K: Biologically active products of stimulated liver macrophages (Kupffer cells). Eur J Biochem 192: 245-261, 1990.

38. Laskin DL, Weinberger B and Laskin JD: Functional heterogeneity in liver and lung macrophages. J Leukoc Biol 70: 163-170, 2001.

39. Roberts RA, Ganey PE, Ju C, Kamendulis LM, Rusyn I and Klaunig JE: Role of the Kupffer cell in mediating hepatic toxicity and carcinogenesis. Toxicol Sci 96: 2-15, 2007.

40. Kruskal JB, Azouz A, Korideck H, et al: Hepatic colorectal cancer metastases: imaging initial steps of formation in mice. Radiology 243: 703-711, 2007.

41. Nishizaki T, Matsumata T, Kanematsu T, Yasunaga C and Sugimachi K: Surgical manipulation of VX2 carcinoma in the rabbit liver evokes enhancement of metastasis. J Surg Res 49: 92-97, 1990.

42. Ito S, Nakanishi H, Hirai T, et al: Quantitative detection of CEA expressing free tumor cells in the peripheral blood of colorectal cancer patients during surgery with real-time RT-PCR on a LightCycler. Cancer Lett 183: 195-203, 2002.

43. Weitz J, Koch M, Kienle P, et al: Detection of hematogenic tumor cell dissemination in patients undergoing resection of liver metastases of colorectal cancer. Ann Surg 232: 66-72, 2000. 